\title{
Impact of trauma centre designation level on outcomes following hemorrhagic shock: a multicentre cohort study
}

\author{
Philippe Dufresne, MSc \\ Lynne Moore, PhD \\ Pier-Alexandre Tardif, MA, MSc \\ Tarek Razek, MD \\ Madiba Omar, MSc \\ Amélie Boutin, PhD \\ Julien Clément, MD
}

This research was presented at the Trauma Association of Canada meeting, April 2015, Calgary, Alta.

Accepted Sept. 12, 2016; Early-released Dec. 1, 2016

\author{
Correspondence to: \\ L. Moore \\ CHU de Québec \\ Université Laval Research Centre \\ Enfant-Jésus Hospital \\ $1401,18^{e}$ rue, local H-012a \\ Québec QC G1J 1 Z4 \\ lynne.moore@fmed.ulaval.ca
}

DOI: $10.1503 /$ cjs.009916
Background: Hemorrhagic shock is responsible for $45 \%$ of injury fatalities in North America, and $50 \%$ of these occur within $2 \mathrm{~h}$ of injury. There is currently a lack of evidence regarding the trajectories of patients in hemorrhagic shock and the potential benefit of level I/II care for these patients. We aimed to compare mortality across trauma centre designation levels for patients in hemorrhagic shock. Secondary objectives were to compare surgical delays, complications and hospital length of stay (LOS).

Methods: We performed a retrospective cohort study based on a Canadian inclusive trauma system (1999-2012), including adults with systolic blood pressure (SBP) $<90 \mathrm{~mm} \mathrm{Hg}$ on arrival who required urgent surgical care $(<6 \mathrm{~h})$. Logistic regression was used to examine the influence of trauma centre designation level on riskadjusted surgical delays, mortality and complications. Linear regression was used to examine LOS.

Results: Compared with level I centres, adjusted odds ratios (and 95\% confidence intervals [CI]) of mortality for level III and IV centres were $1.71(1.03-2.85)$ and 2.25 (1.08-4.73), respectively. Surgical delays did not vary across designation levels, but mean LOS and complications were lower in level II-IV centres than level I centres.

Conclusion: Level I/II centres may offer a survival advantage over level III/IV centres for patients requiring emergency intervention for hemorrhagic shock. Further research with larger sample sizes is required to confirm these results and to identify optimal transport time thresholds for bypassing level III/IV centres in favour of level I/II centres.

Contexte : Le choc hémorragique est responsable de $45 \%$ des décès chez les polytraumatisés en Amérique du Nord, et $50 \%$ de ces décès surviennent dans les 2 h suivant le traumatisme. On ne dispose pas actuellement de données concernant la trajectoire des patients en état de choc hémorragique et les bénéfices potentiels de soins de niveaux I/II pour ces patients. Nous avons voulu comparer la mortalité selon les niveaux de désignation des centres de traumatologie pour les patients en état de choc hémorragique. Les objectifs secondaires étaient de comparer les délais d'accès à la chirurgie, les complications et la durée des séjours hospitaliers.

Méthodes : Nous avons procédé à une étude de cohorte rétrospective basée sur un système de traumatologie inclusif au Canada (1999-2012), incluant des adultes dont la tension artérielle systolique (TAS) était $<90 \mathrm{~mm} \mathrm{Hg}$ à l'arrivée et qui nécessitaient un traitement chirurgical urgent $(<6 \mathrm{~h})$. La régression logistique a été utilisée pour analyser l'influence du niveau de désignation du centre de traumatologie sur le délai d'accès à la chirurgie, la mortalité et les complications ajustés selon le risque. La régression linéaire a été utilisée pour analyser la durée du séjour hospitalier.

Réstulats : Comparativement aux centres de niveau I, les rapports des cotes ajustés (et les intervalles de confiance [IC] de $95 \%$ ) de mortalité pour les centres de niveaux III et IV ont été $1,71(1,03-2,85)$ et 2,25 (1,08-4,73), respectivement. Les délais d'accès à la chirurgie n'ont pas varié en fonction des niveaux de désignation, mais la durée moyenne du séjour hospitalier et les complications étaient moindres dans les centres de niveaux II et IV comparativement aux centres de niveau I.

Conclusion : Les centres de niveaux I/II peuvent offrir des avantages au plan de la survie comparativement aux centres de niveaux III/IV pour les patients en état de choc hémorragique qui ont besoin d'une intervention d'urgence. Il faudra approfondir la recherche auprès d'échantillons de plus grande taille pour confirmer ces résultats et établir les seuils optimaux en termes de temps de transport permettant de passer outre les centres de niveaux III/IV en faveur des centres de niveaux I/II. 
emorrhagic shock following injury is responsible for $45 \%$ of injury fatalities in the United States, ${ }^{1}$ and $50 \%$ of these deaths occur within $2 \mathrm{~h}$ of injury. ${ }^{2,3}$ Surgical or angiographic interventions are standard treatments for hemorrhagic injuries, and time to intervention is an important marker of quality of care for these patients. A delay to definitive care of more than $1 \mathrm{~h}$ is associated with a 3 -fold increase in the odds of death, ${ }^{4,5}$ and every additional minute of prehospital time increases those odds by $5 \% .^{5}$ For this reason, time to definitive care has guided the development of trauma systems.

Organized trauma systems are associated with a $15 \%$ reduction in trauma-related mortality in North America. ${ }^{5-7}$ This is mainly owing to the highly specialized care available in level I/II centres and to the reduced time to definitive care associated with more appropriate prehospital triage and interfacility transfer protocols. ${ }^{5,8,9}$ Trauma patients are transported to the nearest trauma centre for initial stabilization, although prehospital triage protocols dictate bypassing regional trauma centres for major traumas when direct transport to the nearest level I/II centre is possible. ${ }^{10}$ However, because of the time-sensitive nature of hemorrhagic injuries and because all trauma centres theoretically have the capacity to provide definitive surgical care to patients in hemorrhagic shock with no other serious injuries, these patients are often taken to the nearest trauma centre, regardless of the designation level., ${ }^{5,11}$ There is currently a lack of evidence regarding the potential benefit of level I/II care for these patients. ${ }^{12}$

The primary objective of the present study was to compare mortality across trauma centre designation levels for patients in hemorrhagic shock. Secondary objectives were to compare surgical delays, complications and hospital length of stay (LOS). We hypothesized that mortality is lower in level I centres than level IV centres owing to higher volume, greater surgical expertise and the availability of high-technology resources. ${ }^{13} \mathrm{We}$ also hypothesized that level I centres have shorter delays to definitive hemorrhagic control than level IV centres as surgical teams are already on site.

\section{Methods}

\section{Study setting and population}

This retrospective, multicentre cohort study is based on the fully inclusive, mature trauma system in the province of Quebec, Canada. The system consists of 57 adult trauma centres, including 3 level I, 4 level II, 22 level III and 28 level IV centres covering a territory of 1.6 million $\mathrm{km}^{2} .{ }^{14,15}$ Trauma centre designation levels are revised periodically with on-site visits according to American College of Surgeons criteria. ${ }^{10}$ Trauma care services in Quebec are based on transfer agreements between hospitals and a no-refusal transfer policy. ${ }^{5,11}$ Level I/II centres are large, urban hospitals with 24/7 surgical coverage, while level IV centres are mostly small rural hospitals. ${ }^{5,10,11}$

Our study population comprised adults (age $\geq 16 \mathrm{yr}$ ) with a systolic blood pressure $(\mathrm{SBP})<90 \mathrm{~mm} \mathrm{Hg}^{16,17}$ on arrival at the definitive care trauma centre who were undergoing intervention for hemorrhage control (i.e., surgery or angio-intervention within $6 \mathrm{~h}) .{ }^{18}$ Relevant Canadian Classification of Health Interventions (CCI) codes for hemorrhagic control were selected by clinical experts. We excluded patients who were coded dead on arrival or who arrived with no vital signs and died within $30 \mathrm{~min}$ from all analyses. Patients in hemorrhagic shock on arrival who died within $6 \mathrm{~h}$ were included for analyses on mortality if they had major thoracoabdominal injury (Abbreviated Injury Scale [AIS] score $\geq 4$ ) and had a maximum AIS for head injuries $\leq 2$. The study was approved by the Research Ethics Committee of the CHU de Québec and by the Ethics Committee of Research of Université Laval.

\section{Study data}

Data were extracted from the Quebec trauma registry. Each provincial trauma centre is mandated to contribute to the registry according to the following patient inclusion criteria: death following injury, admission to the intensive care unit, hospital stay of 3 days or longer, or transfer from another hospital. Medical archivists extract data from patient files based on protocols proposed by the American College of Surgeons. ${ }^{10}$ Anatomic injuries are coded using the AIS. ${ }^{19}$ Interventions are coded using the CCI. Different mechanisms are used to ensure data quality: yearly ongoing training, 3 meetings per year with key stakeholders, an electronic forum of coding queries and supervision by a data coordinator.

\section{Outcomes}

The primary outcome of interest was in-hospital mortality. Secondary outcomes were in-hospital surgical delay, occurrence of at least 1 complication during the hospital stay and hospital LOS. Surgical delay was calculated in hours from arrival in the emergency department (ED) to the initiation of surgery or angio-intervention and dichotomized using a 1-h cut-off. ${ }^{4,5}$ Complications, including postadmission death, were conditions potentially related to care according to expert consensus, described in detail elsewhere..$^{20} \mathrm{We}$ calculated LOS as the number of days from admission to discharge from the definitive acute care hospital.

\section{Statistical analysis}

To characterize trajectories of care, we described designation levels of first receiving and definitive care centres, the median time to definitive care, the median surgical delay 
(from the ED to the operating table), the proportion of patients with a surgical delay longer than $1 \mathrm{~h}$, and the ratio of angio-interventions to surgery.

Mortality, surgical delay longer than $1 \mathrm{~h}$ and complications were compared across trauma centre designation levels using odds ratios (ORs) derived from multivariate logistic regression models. We compared LOS using geometric mean ratios (GMRs) obtained from a multivariate log-linear regression model based on data from patients who were discharged alive. We adjusted the GMRs, ORs and 95\% confidence intervals (CIs) for sex; age; presence of cardiopathies and/or coagulopathies; SBP on arrival; Glasgow Coma Scale (GCS) score; maximum AIS of injuries to the trunk, the extremities and the head; and presence of penetrating injuries. Adjustments for cardiopathies included congestive heart failure, cardiac arrhythmias, valvular disease and any coagulopathies, which are all components of the Elixhauser Comorbidity Index. ${ }^{21}$

Missing data on surgical delay (3.4\%), SBP (1.5\%) and GCS (15\%) were simulated using multiple imputation with the Markov Chain Monte Carlo method using 10 imputed data sets for each missing data value. The imputation models included the same independent and dependent variables as the analysis models. All analyses were conducted using the 10 imputed data sets, and results were combined using the MIANALYZE procedure in SAS software version 9.4.

\section{Sensitivity analyses}

Analyses were repeated excluding 1) patients with missing data, 2) patients with a severe head injury (head AIS $\geq 3$ ) and 3) patients who received only angio-interventions. We also repeated analyses using a 2- and 4-h cut-off to define emergency surgery.

All statistical analyses were performed using SAS software. All tests were 2 -sided. Statistical significance was set at $5 \%$.

\section{Results}

\section{Study population}

The Quebec trauma registry included 7855 adult patients with $\mathrm{SBP}<90 \mathrm{~mm} \mathrm{Hg}$ on arrival at the trauma centre between 1998 and 2014. Of those patients, 732 had an intervention for hemorrhagic control within $6 \mathrm{~h}$ of their arrival in the ED. An additional 190 patients (total 922 patients) arrived with a major extracranial injury (head AIS $\leq 2$ and trunk AIS $\geq 4$ ) and died without receiving an intervention $30 \mathrm{~min}$ to $6 \mathrm{~h}$ following arrival (Fig. 1 and Table 1).

\section{Patient trajectories}

The majority of patients in hemorrhagic shock $(n=493$, $67.3 \%$ ) received definitive care in a level I or level II trauma centre (Table 2), of whom $83.2 \%$ were transported

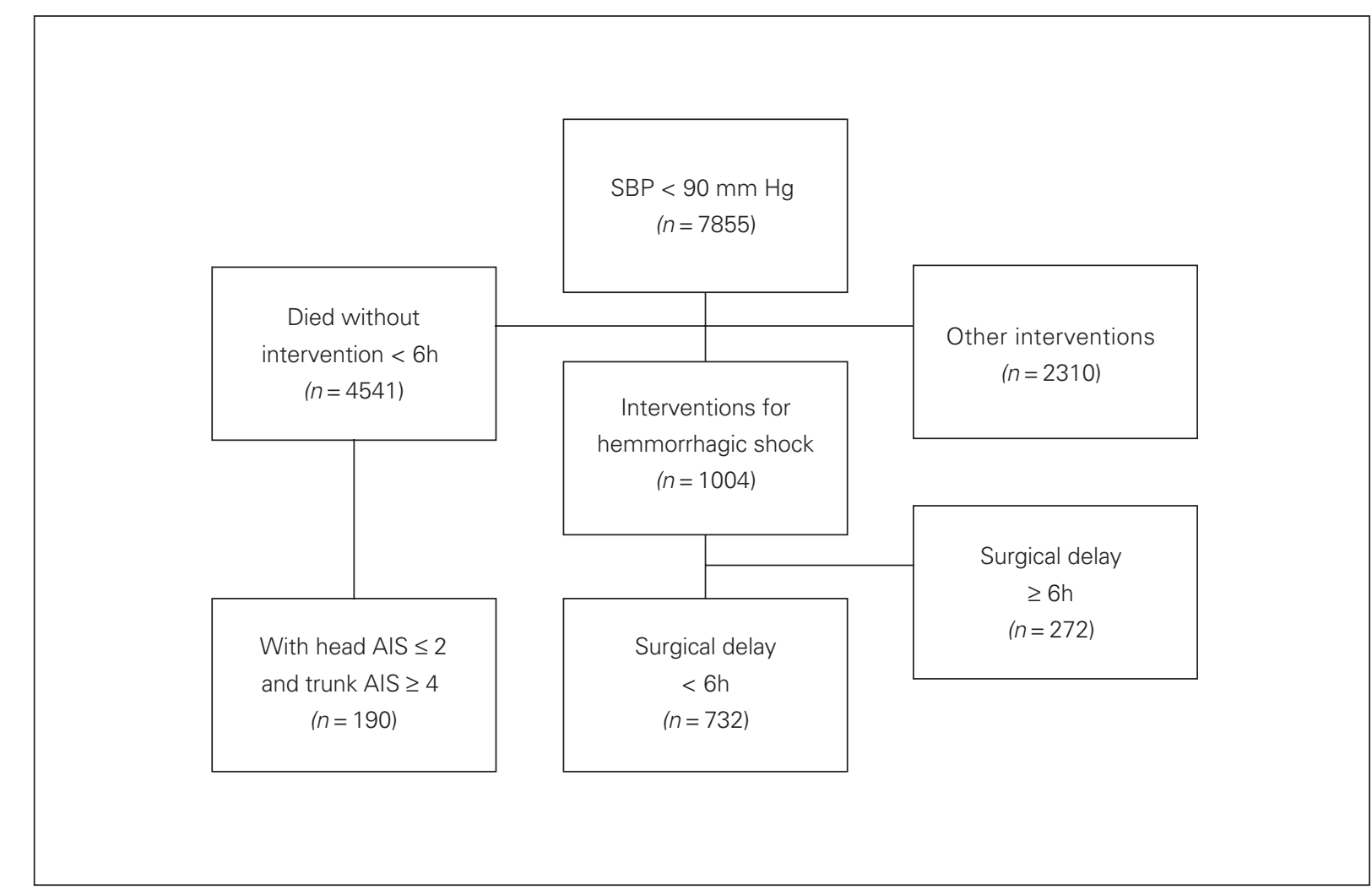

Fig. 1. Selection of the study population. AIS = Abbreviated Injury Scale; SBP = systolic blood pressure. 
directly. Only 50 (6.8\%) patients received definitive care in a level IV centre. Crude median surgical delay for patients directly admitted to a level IV centre $(1.9 \mathrm{~h})$ was similar to that of patients directly admitted to a level III $(1.7 \mathrm{~h})$ or level I/II centre $(1.8 \mathrm{~h})$. Angio-intervention was used in $118(23.9 \%)$ patients in level I/II centres, whereas

\begin{tabular}{|c|c|c|c|c|c|}
\hline \multirow[b]{2}{*}{ Characterisitc } & \multirow[b]{2}{*}{ Entire cohort } & \multicolumn{4}{|c|}{ Trauma centre level; no. (\%) } \\
\hline & & I & II & III & IV \\
\hline No. of patients & $732(100)$ & 285 (38.9) & $208(28.4)$ & $189(25.8)$ & $50(6.8)$ \\
\hline Female sex & $211(28.8)$ & $80(28.1)$ & $56(26.9)$ & $59(31.2)$ & $16(32.0)$ \\
\hline \multicolumn{6}{|l|}{ Age, yr } \\
\hline $16-54$ & 519 (70.9) & $213(74.7)$ & $148(71.2)$ & $127(67.2)$ & $31(62.0)$ \\
\hline $55-64$ & 90 (12.3) & $28(9.8)$ & 29 (13.9) & 26 (13.8) & $7(14.0)$ \\
\hline $65-74$ & $72(9.8)$ & $31(10.9)$ & $18(8.7)$ & $17(9.0)$ & $6(12.0)$ \\
\hline$\geq 75$ & $51(7.0)$ & $9(3.2)$ & $8(3.9)$ & $19(10.1)$ & $6(12.0)$ \\
\hline \multicolumn{6}{|l|}{ Mechanism of injury } \\
\hline Motor vehicle collision & $423(57.8)$ & $143(50.2)$ & $141(67.8)$ & $112(59.3)$ & $27(54.0)$ \\
\hline Fall & $57(7.8)$ & $4(1.4)$ & $4(2.1)$ & $11(5.8)$ & $7(14.0)$ \\
\hline Penetrating Injury & $184(25.1)$ & $19(6.7)$ & $15(7.2)$ & $41(21.7)$ & $11(22.0)$ \\
\hline Blunt object and others & $68(9.3)$ & $97(34.0)$ & 35 (16.8) & $25(13.2)$ & $5(10.0)$ \\
\hline \multicolumn{6}{|l|}{$\mathrm{SBP}, \mathrm{mm} \mathrm{Hg}{ }^{\dagger}$} \\
\hline$<50$ & $49(6.7)$ & $18(6.3)$ & $15(7.2)$ & $16(8.5)$ & $0(0)$ \\
\hline $50-75$ & $279(38.1)$ & 109 (38.3) & 76 (36.5) & 79 (41.8) & $15(30.0)$ \\
\hline $76-89$ & $404(55.2)$ & $158(55.4)$ & $117(56.3)$ & $94(49.7)$ & $35(70.0)$ \\
\hline \multicolumn{6}{|l|}{ GCS scoret } \\
\hline $3-8$ & $193(26.4)$ & 92 (32.3) & $62(29.8)$ & $31(16.4)$ & $9(18.0)$ \\
\hline $9-12$ & 75 (10.2) & 37 (12.9) & $19(9.1)$ & $15(7.9)$ & $2(4.0)$ \\
\hline $13-15$ & $464(63.4)$ & $156(54.7)$ & $127(61.1)$ & $143(75.7)$ & $39(78.0)$ \\
\hline \multicolumn{6}{|l|}{$\begin{array}{l}\text { Body region of the most severe } \\
\text { injury }\end{array}$} \\
\hline Head & $179(24.5)$ & $79(27.7)$ & $59(28.4)$ & $34(18.0)$ & $7(14.0)$ \\
\hline Thorax & $225(30.7)$ & 99 (34.7) & $63(30.3)$ & $51(27.0)$ & $12(24.0)$ \\
\hline Abdomen & $220(30.1)$ & $66(23.2)$ & $52(25.0)$ & $77(40.7)$ & $25(50.0)$ \\
\hline Spine & $19(2.6)$ & $12(4.2)$ & $5(26.3)$ & $1(0.5)$ & $1(2.0)$ \\
\hline Extremities & $89(12.2)$ & $9(3.2)$ & $8(3.8)$ & $26(13.8)$ & $5(10.0)$ \\
\hline \multicolumn{6}{|l|}{$\begin{array}{l}\text { Maximum AIS to the trunk, neck } \\
\text { and limbs }\end{array}$} \\
\hline $1-2$ & $169(45.7)$ & $12(5.7)$ & $16(5.7)$ & $24(13.0)$ & $14(28.0)$ \\
\hline 3 & $54(14.6)$ & 67 (38.8) & 109 (38.8) & $64(34.6)$ & $20(40.0)$ \\
\hline 4 & $54(14.6)$ & $83(34.9)$ & $98(34.9)$ & $66(35.7)$ & $12(24.0)$ \\
\hline $5-6$ & $93(25.1)$ & 40 (19.8) & $58(20.6)$ & $31(16.8)$ & $4(8.0)$ \\
\hline \multicolumn{6}{|l|}{ Maximum AIS to the head } \\
\hline $1-2$ & $66(9.2)$ & $76(47.5)$ & $45(38.5)$ & $39(50.0)$ & $9(60.0)$ \\
\hline 3 & $260(36.2)$ & $16(10.0)$ & $22(18.8)$ & $15(19.2)$ & $1(6.7)$ \\
\hline 4 & $259(36.1)$ & $24(15.0)$ & $12(10.3)$ & $14(18.0)$ & $4(26.7)$ \\
\hline $5-6$ & $133(18.5)$ & $44(27.5)$ & $38(32.5)$ & $10(12.8)$ & $1(6.7)$ \\
\hline Cardiopathies and coagulopathies & $96(13.1)$ & $25(8.8)$ & 38 (18.3) & $30(15.9)$ & $3(6.0)$ \\
\hline \multicolumn{6}{|l|}{ Residential remoteness $\dagger$} \\
\hline Metropolitain $\ddagger$ & $277(41.0)$ & $178(64.0)$ & $50(24.9)$ & $42(17.5)$ & $7(16.3)$ \\
\hline Other regions§ & $117(17.3)$ & $42(15.1)$ & 66 (32.8) & $9(5.9)$ & $0(0)$ \\
\hline Agglomerations $\rrbracket$ & $79(11.7)$ & $9(3.2)$ & $31(15.4)$ & $29(19.0)$ & $10(23.3)$ \\
\hline Small town and rural areas** & $202(29.9)$ & 49 (17.6) & 54 (26.9) & $73(47.7)$ & $26(60.5)$ \\
\hline $\begin{array}{l}\text { AIS = Abbreviated Injury Scale; GCS = C } \\
\text { *Data simulated using multiple imputati } \\
\text { †Data missing for } 57 \text { patients. } \\
\text { †Population size }>1000000 . \\
\text { \$Population size } 100000-1000000 \text {. } \\
\text { IPopulation size } 10000-100000 . \\
\text { ** Population size < } 10000 .\end{array}$ & Jow Coma Scale; S & systolic blood & & & \\
\hline
\end{tabular}


only 3 patients $(6.0 \%)$ had nonsurgical hemorrhagic control in level IV centres (Table 2).

\section{Outcomes}

Overall, 190 patients (20.6) died within $6 \mathrm{~h}$ of arrival before intervention, and a further 147 patients (15.9\%) died after surgery or angio-intervention. Patients treated in a level III trauma centre had an adjusted odds of dying that was $70 \%$ higher than those treated in a level I centre, whereas the odds for patients treated at level IV centres was 2.3 times higher (Table 3 ).

The adjusted odds of a surgical delay longer than $1 \mathrm{~h}$ were higher in level II, III and IV centres than level I centres, but observed differences did not reach statistical significance (Table 3).

Overall, 53.0\% (388 of 732) of eligible patients experienced at least 1 complication following surgery or angiointervention. The most common complications were hospital-acquired pneumonia and surgical site infection (Fig. 2). The adjusted odds of complications for patients receiving definitive care in level II, III and IV centres was less than half that observed for patients treated in a level I centre (Table 3).
Observed mean LOS in survivors was 29.3 (median 18) days. Patients who received definitive care in a level II, III, or IV centre had a mean LOS $26 \%, 50 \%$ and $72 \%$ shorter, respectively, than patients who were admitted to a level I centre (Table 3).

\section{Sensitivity analyses}

The significantly lower odds of risk-adjusted mortality, higher odds of complications and longer LOS observed in the complete study population remained stable when we restricted analyses to patients with no missing data and to patients with no major head injury. The odds of death were reduced when we excluded patients who received exclusively angio-intervention from our analysis. Odds ratios for mortality were 1.1, 1.1, and 1.2, for level II, III and IV centres, respectively, compared with level I centres. Conclusions remained unchanged when we used a 2- or 4-h cut-off instead of a 6-h cut-off to define emergency surgery.

\section{Discussion}

In this multicentre cohort study, patients treated for hemorrhagic shock in a level IV trauma centre had a risk-adjusted

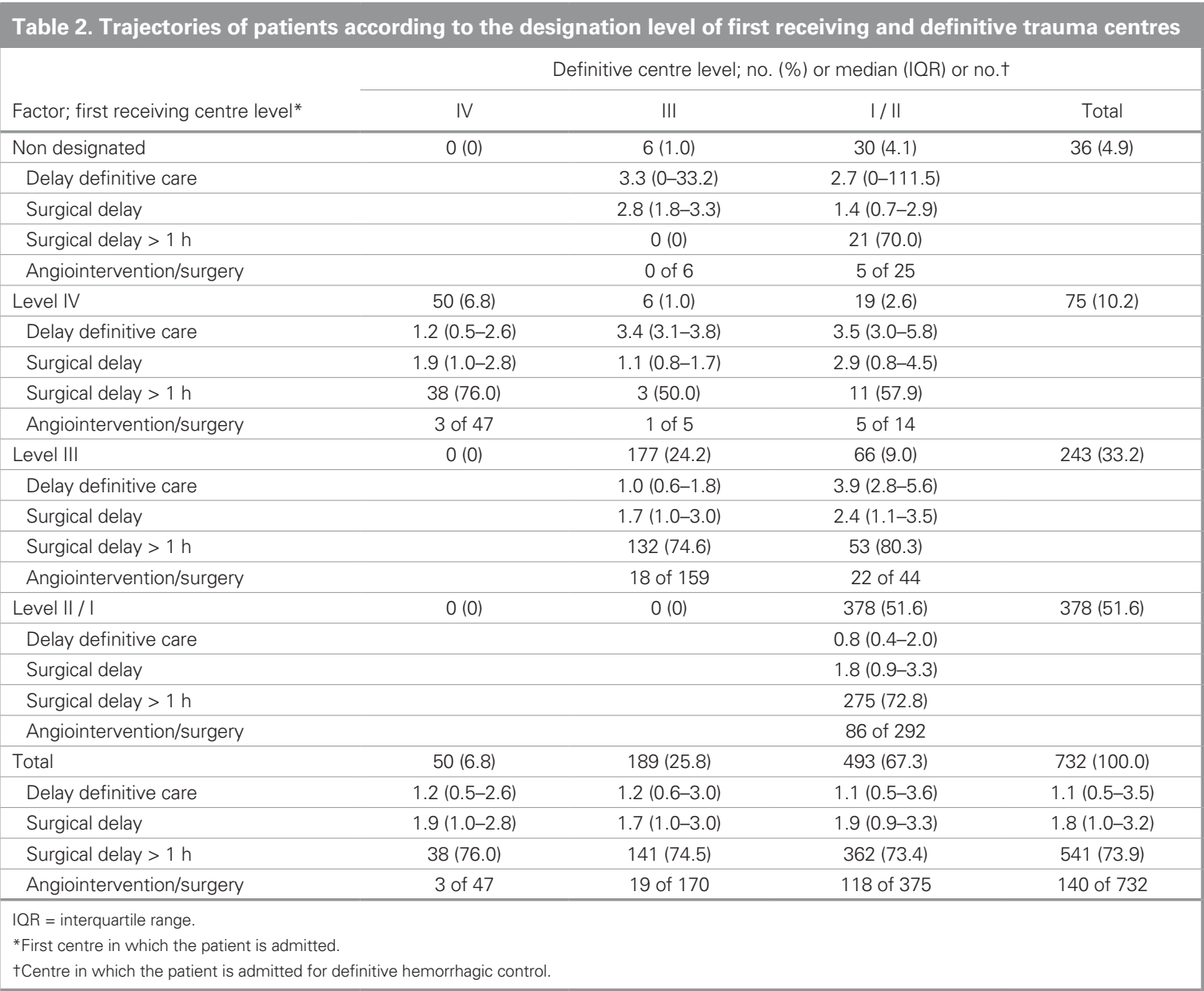


odds of death 2.3 times that of patients treated in a level I centre. The OR for level III centres was $70 \%$ higher. The proportion of patients receiving an intervention for hemorrhagic control more than $1 \mathrm{~h}$ after their arrival was higher in level II, III and IV centres than in level I centres, but the difference did not reach statistical significance. Finally, complications and mean LOS were significantly greater in level I centres than in level II, III and IV centres.

Only 1 out of 4 patients received their intervention for hemorrhagic control within $1 \mathrm{~h}$ of arrival. These data suggest that trajectories for patients with hemorrhagic shock within our trauma system are suboptimal.

The increase in mortality for level IV centres observed in this study is consistent with those reported in the literature. Several studies have observed higher mortality in level IV centres than level I centres in integrated trauma systems for general injury admissions and for traumatic brain injury., 52 Previous studies have reported that as hospital volume increases, the odds of dying decreases for general injury admissions and specifically for patients in hemorrhagic shock. ${ }^{23,24}$ The increase in mortality observed in our study is clinically important and could be explained by higher surgical volume, greater expertise and availability of resources, such as imagery and angio-intervention. ${ }^{10,11}$ This hypothesis is supported by the reduction in mortality when patients

Table 3. Adjusted* odds ratios for death, surgical delay $>1 \mathrm{~h}$

and complications and geometric mean ratios for length of

hospital stay, by trauma centre designation level

\begin{tabular}{|c|c|c|c|}
\hline $\begin{array}{l}\text { Outcome; trauma } \\
\text { centre level }\end{array}$ & $\begin{array}{l}\text { No. }(\%) \text { or } \\
\text { mean } \pm \text { SD }\end{array}$ & $\begin{array}{l}\text { Crude OR or } \\
\text { GMR }(95 \% \mathrm{Cl})\end{array}$ & $\begin{array}{l}\text { Adjusted OR or } \\
\text { GMR }(95 \% \mathrm{Cl})\end{array}$ \\
\hline \multicolumn{4}{|l|}{ Death $(n=922)$} \\
\hline I & $83(26.0)$ & 1.00 & 1.00 \\
\hline II & 76 (32.8) & $1.39(0.96-2.01)$ & $1.35(0.83-2.17)$ \\
\hline III & 132 (46.6) & $2.49(1.77-3.50)$ & $1.71(1.03-2.85)$ \\
\hline IV & $46(52.3)$ & $3.11(1.91-5.07)$ & $2.25(1.08-4.73)$ \\
\hline \multicolumn{4}{|l|}{$\begin{array}{l}\text { Surgical delay > } \\
1 \mathrm{~h}(n=732)\end{array}$} \\
\hline I & $195(68.4)$ & 1.00 & 1.00 \\
\hline II & 165 (79.3) & 1.89 (1.22-2.86) & $1.52(0.94-2.44)$ \\
\hline III & 141 (74.6) & 1.35 (0.89-2.04) & $1.19(0.74-1.92)$ \\
\hline IV & $38(76.0)$ & $1.45(0.73-2.94)$ & $1.15(0.53-2.50)$ \\
\hline \multicolumn{4}{|l|}{$\begin{array}{l}\text { Complications } \\
(n=732)\end{array}$} \\
\hline I & $175(61.4)$ & 1.00 & 1.00 \\
\hline ॥ & $111(53.4)$ & $1.03(0.77-1.39)$ & $0.48(0.31-0.74)$ \\
\hline III & 85 (44.9) & $0.71(0.53-0.96)$ & $0.48(0.30-0.75)$ \\
\hline IV & $14(28.0)$ & $0.41(0.27-0.64)$ & $0.32(0.15-0.70)$ \\
\hline \multicolumn{4}{|l|}{ LOS, d $(n=583)$} \\
\hline I & $25.5 \pm 2.5$ & 1.00 & 1.00 \\
\hline II & $19.7 \pm 2.5$ & $0.78(0.63-0.95)$ & $0.74(0.62-0.90)$ \\
\hline III & $12.1 \pm 3.1$ & $0.48(0.39-0.58)$ & $0.50(0.41-0.61)$ \\
\hline IV & $5.95 \pm 2.7$ & $0.23(0.17-0.32)$ & $0.28(0.21-0.39)$ \\
\hline \multicolumn{4}{|c|}{$\begin{array}{l}\mathrm{Cl}=\text { confidence interval; } \mathrm{GMR}=\text { geometric mean ratio; } \mathrm{LOS}=\text { length of stay; OR = odds } \\
\text { ratio; } \mathrm{SD}=\text { standard deviation. } \\
\text { *Adjusted for sex, systolic blood pressure, age, cardiopathies and coagulopathies, } \\
\text { Glasgow Coma Scale score, maximum Abbreviated Injury Scale score to the trunk, limbs } \\
\text { and head and penetrating injuries. }\end{array}$} \\
\hline
\end{tabular}

who received only angio-interventions were excluded from the sensitivity analysis. Observed increases in complication rates for level I/II centres have also been observed for general injury admission $\mathrm{s}^{25}$ and could be due to the higher intensity of care in these centres, greater exposure to hospitalacquired infections or to under-reporting of complications in level IV centres owing to lack of systematic screening practices (e.g., screening for deep vein thrombosis). Our results of longer LOS in trauma centres with a higher designation level also corroborate previous studies in general injury admissions ${ }^{26}$ and may again be explained by higher intensity of care in higher level centres or to difficulty accessing postdischarge care facilities in urban areas where patients are also more likely to be affected by social deprivation, restricting access to natural caregivers. ${ }^{27}$ The longer LOS observed in level I centres may also be related to their higher incidence of complications.

\section{Strengths and limitations}

Since participation in the provincial trauma registry is mandatory for all trauma centres and more than $90 \%$ of major trauma is treated within the trauma system, this study provides excellent representation of patients with hemorrhagic shock who survive transport to a trauma centre. ${ }^{28}$ Other strengths include the availability of extensive clinical information for risk adjustment and the simulation of missing data, which enabled us to include all eligible patients.

This study does have limitations, which should be considered in the interpretation of our results. First, despite the use of 16 years of data in a province-wide inclusive trauma system, we had limited statistical power to detect clinically significant differences in surgical delays across trauma centre designation levels. Given the low frequency of patients in hemorrhagic shock requiring emergency intervention, sufficient sample sizes would require data across several

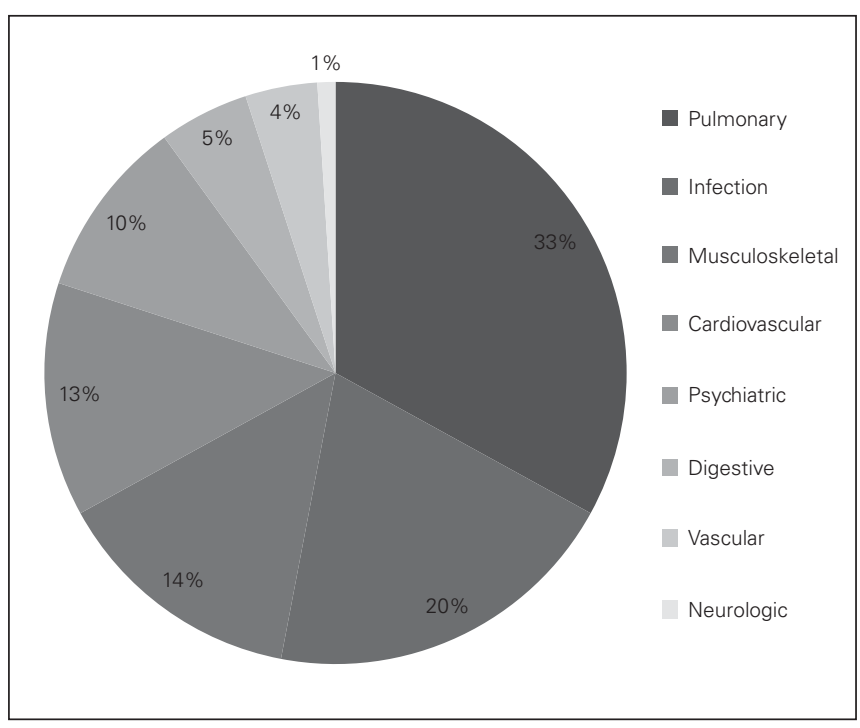

Fig. 2. Frequency of complications. 
health care systems, leading to significant heterogeneity in trajectories of care. This highlights the fact that patients in hemorrhagic shock represent only a small proportion of major trauma admissions and that undue emphasis should not be placed on this patient group in the organization of Canadian trauma systems. Second, we used $\mathrm{SBP}<90 \mathrm{~mm} \mathrm{Hg}$ and intervention within $6 \mathrm{~h}$ or less as a proxy for hemorrhagic shock requiring emergency surgery in the absence of more comprehensive information. This may have led to selection bias that would have caused an underestimation of the influence of trauma centre designation level on outcomes in these patients. Third, a large proportion of patients had missing data on SBP, GCS or surgical delay. We simulated missing data using multiple imputation, which relies on the postulate that data are missing at random (i.e., the probability of being "missing" depends only on available data). However, we are confident that information on patient demographics, injury characteristics and trajectories of care explains the missing data mechanism well, a hypothesis supported by our sensitivity analyses and the validity of parameter estimates based on multiple imputation in simulation studies of trauma registry data. ${ }^{29-31}$ Fourth, trauma registries are subject to data quality problems, which may have led to misclassification of outcome variables, possibly leading to an underestimation of ORs or GMRs. Suboptimal data quality may also have led to misclassification of adjustment variables, which could lead to residual confounding and an over- or underestimation of ORs or GMRs. Notably, comorbidities are notoriously under-reported in clinical registries, and coagulopathies are particularly difficult to identify. However, quality control of the registry data described previously ensures the extent of this bias is limited, and previous data quality checks suggest that data accuracy in the trauma registry compared with complete patient charts is greater than $95 \%$. Nevertheless, this applies only to information reported in the chart. Fifth, the results of the present study are likely to generalize well to trauma systems with similar proportions of penetrating trauma and geographical challenges, such as Australia and large, rural US states, but may not generalize well to urban US trauma systems where the frequency of penetrating injury is much higher. Finally, the majority of deaths following hemorrhagic injury occur at the scene of the accident, and future research should aim to integrate information on prehospital deaths to further advance knowledge on optimal trauma system configuration for these patients.

\section{Conclusion}

The results of this multicentre cohort study suggest that level I and II centres may offer a survival advantage over level III and IV centres for patients requiring emergency intervention for hemorrhagic shock. Factors explaining this advantage require further investigation but may include shorter surgical delays (clinically but not statis- tically significant), volume expertise and technical availability (i.e., imagery and angio-intervention). Further research with larger sample sizes is required to confirm these results and to identify optimal transport time thresholds for bypassing level III/IV centres in favour of level I/II centres.

Acknowledgements: The authors thank the technical staff at the CHU research centre for their methodological support.

Affiliations: From the Population Health and Optimal Health Practices Research Unit, Trauma, Emergency, Critical Care Medicine, CHU de Québec, Université Laval Research Centre, Québec, Que., (Dufresne, Moore, Tardif, Omar, Boutin); the Department of Social and Preventive Medicine, Université Laval, Québec, Que., (Dufresne, Moore, Tardif, Omar, Boutin); the Department of Sugery, McGill University, Montreal, Que., (Razek); and the Department of Surgery, Université Laval, Québec, Que. (Clément).

Funding: Canadian Institutes of Health Research New Investigator Award (LM, HTS, AT), Fonds de Recherche du Québec - Santé award (FL) and Canadian Institutes of Health Research operating grant (LM; \#110996).

\section{Competing interests: None declared.}

Contributors: P. Dufresne, L. Moore and J. Clément designed the study. L. Moore and J. Clément acquired the data, which all authors analyzed. P. Dufresne, L. Moore and J. Clément wrote the article, which all authors reviewed and approved for publication.

\section{References}

1. Sauaia A, Moore FA, Moore EE, et al. Epidemiology of trauma deaths: a reassessment. 7 Trauma 1995;38:185-93.

2. Asensio JA, Trunkey DD. Current therapy of trauma and surgical critical care. Philadelphia, PA: Elsevier/Saunders; 2016.

3. Tisherman SA, Schmicker RH, Brasel KJ, et al. Detailed description of all deaths in both the shock and traumatic brain injury hypertonic saline trials of the Resuscitation Outcomes Consortium. Ann Surg 2015;261:586-90.

4. Sampalis JS, Lavoie A, Williams JI, et al. Impact of on-site care, prehospital time, and level of in-hospital care on survival in severely injured patients. 7 Trauma 1993;34:252-61.

5. Sampalis JS, Denis R, Lavoie A, et al. Trauma care regionalization: a process-outcome evaluation. 7 Trauma 1999;46:565-79.

6. Celso B, Tepas J, Langland-Orban B, et al. A systematic review and meta-analysis comparing outcome of severely injured patients treated in trauma centers following the establishment of trauma systems. $\mathcal{F}$ Trauma 2006;60:371-8.

7. Cameron PA, Gabbe BJ, Cooper DJ, et al. A statewide system of trauma care in Victoria: effect on patient survival. Med F Aust 2008;189:546-50.

8. Clark DE, Winchell RJ, Betensky RA. Estimating the effect of emergency care on early survival after traffic crashes. Accid Anal Prev 2013;60:141-7.

9. Harmsen AM, Giannakopoulos GF, Moerbeek PR, et al. The influence of prehospital time on trauma patients outcome: a systematic review. Injury 2015;46:602-9.

10. Task Force of the Committee on Trauma, American College of Surgeons. Resources for optimal care of the injured patient: an update. Bull Am Coll Surg 1990;75:20-9.

11. Institut national d'excellence en santé et en services sociaux (INESSS) 2012. Les caractéristiques, l'historique et l'implantation du continuum de services en traumatologie du Québec (1991 - 2012). Available: www inesss.qc.ca/fileadmin/doc/INESSS/Rapports/Traumatologie/INESSS _historique_CST.pdf (accessed 2016 July 11).

12. Lavoie ABG, Lapointe J. Avis sur les critères de triage préhospitalier en traumatologie 2013. Avaialable: www.inesss.qc.ca/fileadmin 
/doc/INESSS/Rapports/Traumatologie/INESSS_Criteres_triage_ prehospitalier_traumatologie.pdf (accessed 2016 Apr. 8).

13. Dimick JB, Cowan JA Jr, Colletti LM, et al. Hospital teaching status and outcomes of complex surgical procedures in the United States. Arch Surg 2004;139:137-41.

14. Moore L, Turgeon AF, Emond M, et al. Definition of mortality for trauma center performance evaluation: a comparative study. Crit Care Med 2011;39:2246-52.

15. Moore L, Hanley JA, Turgeon AF, et al. Evaluation of the long-term trend in mortality from injury in a mature inclusive trauma system. World 7 Surg 2010;34:2069-75.

16. Alberta Trauma Registry. Foothills Medical Centre Performance Indicators 2003. Avaliable: www.albertahealthservices.ca/ps-1005358-2002 -2003-crha-trauma-report.pdf (accessed 2016 May 17).

17. Parks JK, Elliott AC, Gentilello LM, et al. Systemic hypotension is a late marker of shock after trauma: a validation study of Advanced Trauma Life Support principles in a large national sample. Am 7 Surg 2006;192:727-31.

18. Lipsky AM, Gausche-Hill M, Henneman PL, et al. Prehospital hypotension is a predictor of the need for an emergent, therapeutic operation in trauma patients with normal systolic blood pressure in the emergency department. 7 Trauma 2006;61:1228-33.

19. Gennarelli TA, American Association for Automotive Medicine. Committee on Injury Scaling. Abbreviated Injury Scale. Arlington Heights, IL, USA: American Association for Automotive Medicine; 1985 .

20. Moore L, Lauzier F, Stelfox HT, et al. Complications to evaluate adult trauma care: an expert consensus study. 7 Trauma Acute Care Surg 2014;77:322-9.

21. Elixhauser A, Steiner C, Harris DR, et al. Comorbidity measures for use with administrative data. Med Care 1998;36:8-27.
22. Bell TM, Boustany KC, Jenkins PC, et al. The relationship between trauma center volume and in-hospital outcomes. F Surg Res 2015; 196:350-7.

23. Minei JP, Fabian TC, Guffey DM, et al. Increased trauma center volume is associated with improved survival after severe injury: results of a Resuscitation Outcomes Consortium study. Ann Surg 2014;260:456-64.

24. Bell TM, Boustany KC, Jenkins PC, et al. The relationship between trauma center volume and in-hospital outcomes. 7 Surg Res 2015; 196:350-7.

25. Moore L, Lauzier F, Stelfox HT, et al. Validation of complications selected by consensus to evaluate the acute phase of adult trauma care: a multicenter cohort study. Ann Surg 2015;262: 1123-9.

26. Moore L, Stelfox HT, Turgeon AF, et al. Hospital length of stay after admission for traumatic injury in Canada: a multicenter cohort study. Ann Surg 2014;260:179-87.

27. Cisse B ML, Batomen Kuimi BL, Teegwende VP, et al. Impact of socio-economic status on unplanned readmission following injury: a multicenter cohort study. Injury 2016;47:1083-90.

28. Kuimi BL, Moore L, Cisse B, et al. Access to a Canadian provincial integrated trauma system: A population-based cohort study. Injury 2015;46:595-601.

29. Moore L, Lavoie A, LeSage N, et al. Multiple imputation of the Glasgow Coma Score. 7 Trauma 2005;59:698-704.

30. Moore L, Hanley JA, Turgeon AF, et al. A multiple imputation model for imputing missing physiologic data in the national trauma data bank. 7 Am Coll Surg 2009;209:572-9.

31. Moore L, Hanley JA, Lavoie A, et al. Evaluating the validity of multiple imputation for missing physiological data in the national trauma data bank. 7 Emerg Trauma Shock 2009;2:73-9. 